\title{
68. Changes of the Cortical Layer of the Egg of Oryzias latipes at the Time of Fertilization.)
}

\author{
By Toki-o Yамамото. \\ Zoological Institute, Faculty of Science, Tokyo Imperial University. \\ (Comm. by N. YATSU, M.I.A., Oct. 12, 1939.)
}

Comparatively few works have hitherto appeared upon the physiological changes occurring in the teleost eggs at the time of fertilization. This may be due to the fact that the fish eggs lose in water their fertilizability within a few minutes. For this reason 'dry' fertilization has been recommended. For physiological studies of fertilization it is desirable to keep the unfertilized eggs in fertilizable condition as long as possible. I found that this can be done by keeping the eggs in the isotonic Ringer's solution or in the isotonic balanced salt solution. The egg of Oryzias latipes is isotonic to $\mathrm{M} / 7.5 \mathrm{NaCl}$ solution (from my unpublished data). In M/7.5 Ringer's solution (M/7.5 $\mathrm{NaCl} 100+\mathrm{M} / 7.5$ $\mathrm{KCl} 2.0+\mathrm{M} / 11 \mathrm{CaCl}_{2} 2.1, \mathrm{pH}$ 7.3) the eggs are fertilizable for a number of hours, while they lose this capacity within a few minutes when in tap water. Fertilization processes and the development go on quite normally in Ringer's solution and larvae hatch out in it.

In the unfertilized Oryzias egg the egg membrane or the chorion is present, which after fertilization is lifted up forming the perivitelline space. The chorion has a micropyle at the animal pole. Beneath the chorion is a cortical layer of the egg proper containing numerous oil droplets. Careful observation shows that the cortical alveoli, each measuring $10-40 \mu$ in diameter, are evenly embedded in the cortex. They have an index of refraction different from that of oil droplets. Ripe unfertilized eggs appear less transparent than the fertilized ones partly because of the presence of the cortical alveoli and partly because of the semi-transparency of the chorion which becomes transparent after fertilization.

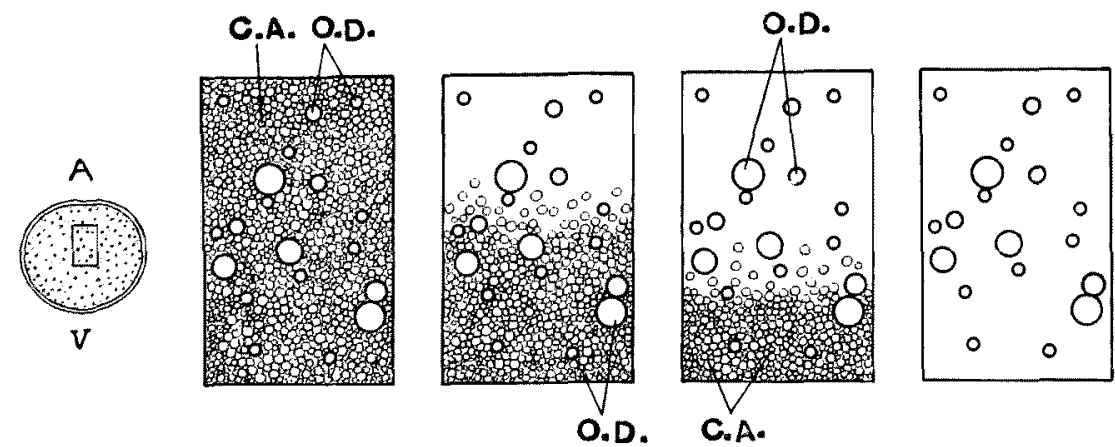

Fig. 1. Breakdown of cortical alveoli of Oryzias egg at the time of fertilization. A, animal pole; V, vegetal pole; C. A., cortical alveoli; O. D., oil droplets.

1) Partly aided by a grant from the Japan Society for the Promotion of Scientific Research, to which my thanks are due. 
During the fertilization process the cortical alveoli break down in a wave-like fashion in about three minutes at $23^{\circ} \mathrm{C}$, beginning at the animal pole and ending at the vegetal pole (Fig. 1). The elevation of the chorion takes the same course as that of the breaking down of the cortical alveoli. The membrane is first soft and hardens gradually. Thus the bipolar differentiation slowly takes place. Numerous oil droplets in the cortex fuse together and migrate toward the vegetal pole.

It was found that the presence of $\mathrm{Ca}$ ions is a sine qua non condition for the fertilization. As stated before the eggs are fertilizable in the isotonic Ringer's solution for a number of hours, but if unfertilized eggs are put into Ca-free Ringer's solution for ten minutes and then inseminated in the solution, eggs are no longer fertilized. If, however, they are put back into Ringer's solution all are fertilized. The same is true in solutions of $\mathrm{Na}$-salts whose anions are $\mathrm{Ca}$ precipitant. When unfertilized eggs are put into the isotonic solutions of $\mathrm{Na}_{2}$-oxalate $(\mathrm{M} / 11)$ or $\mathrm{Na}_{3}$-citrate $(\mathrm{M} / 15)$ for ten minutes and then inseminated in the solutions no eggs are fertilized. If the same eggs are washed with $M / 7.5$ Ringer's solution and then inseminated, the majority of eggs are fertilized. It should here be remarked that the normal fertilization in fresh water is caused by the $\mathrm{Ca}$ ions contained between the chorion and the cortex.

The breakdown of cortical alveoli and the subsequent membrane elevation can also be induced by agents of artificial parthenogenesis. When the cortex of the ripe unfertilized eggs in the isotonic Ringer's solution are pricked with a fine glass needle, the breakdown of cortical alveoli begins at the spot of stimulation and completes at the antipodes. The puncture at the vegetal pole, therefore, causes the dissolution of the cortical alveoli taking a reverse course. Nevertheless, the formation of the blastodisc at the animal pole and the migration of oil droplets toward the vegetal pole take place normaly. Most of eggs activated by puncture did not cleave at all, only some of them having reached the 2-cell stage." When ripe unfertilized eggs are treated with the isotonic $\mathrm{Na}_{2}$-oxalate solution for ten minutes and then they are pricked with a needle in the solution, no egg is activated. If the eggs thus treated are put back into the Ringer's solution, the cortical alveoli break down and the egg membrane is elevated. When the ripe eggs are exposed to $45^{\circ} \mathrm{C}$ in the isotonic Ringer's solution for one minute and put back into Ringer's solution at room temperature, the eggs are activated and the blastodise is formed. Thermally activated eggs showed no normal cleavage.

Importance of the cortical change at the time of fertilization has long been recognized in echinoderm eggs. Experiments of Just (1919, $1923,1929)$ on the ova of sand-dollar and sea-urchins indicate that both the initiation of development and membrane elevation are dependent upon a cortical change. The exact nature of the change has, however, been unknown. Recently Moser (1939) has shown in sea-urchin eggs

1) When unfertilized eggs are pricked with a fine needle smeared with blood, some eggs show normal cleavage and develop as far as the blastula stage. 
that granules embedded in the cortex break down on insemination in a wave-like fashion, beginning at the place of sperm entry and ending at the antipodes. This change is completed within ten seconds. The elevation of fertilization membrane goes on hand in hand with the cortical change. Moser was also able to induce such change by parthenogenetic agents.

In teleost eggs works on the cortical change at the time of fertilization are not many. Kagan (1935) found in Fundulus that ' platelets' embedded in the cortex of unfertilized eggs disappear after fertilization. The wave-like breakdown was not noticed. Tchou and Chen's observations (1936) on fertilization in goldfish are chiefly based on the fixed material. They, however, clearly saw that the cortical alveoli are eliminated on fertilization, starting from the animal pole and completing at the opposite pole.

In conclusion it may be stated that the wave-like breakdown of the cortical alveoli is the most important feature of the fertilization of the teleost eggs. Other changes such as membrane elevation and the bipolar differentiation can be considered as the consequence of this phenomenon.

\section{Literature.}

Just, E. E. 1919 The fertilization reaction in Echinarachnius parma. I. Cortical response of the egg to insemination. Biol. Bull. vol. 36, p. 1.

1923 ditto VI. The necessity of the egg cortex for fertilization. Biol. Bull.

44, p. 1.

1929 The fertilization-reaction in eggs of Paracentrotus and Echinus. Biol. Bull. 57, p. 326 .

Kagan, B. M. 1935 The fertilizable period of the eggs of Fundulus heteroclitus and some associated phenomena. Biol. Bull. vol. 69 , p. 185.

Moser, F. 1939 Studies on a cortical layer response to stimulating agents in the Arbacia egg. I. Response to insemination. J. Exp. Zool. vol. 80, p. 423.

1939 ditto II. Response to chemical and physical agents. J. Exp. Zool. vol. 80, p. 447.

Tchou, S. and C. H. Chen 1936 Fertilization in goldfish. Contr. Inst. Zool. Nat. Acad. Peiping. vol. 3 , no. 2 , p. 35 . 